Sakarya Üniversitesi İlahiyat Fakültesi Dergisi

Journal of Sakarya University Faculty of Theology

ISSN: 2146-9806 | e-ISSN: 1304-6535

Cilt/Volume: 23, Sayı/Issue: 43, Y11/Year: 2021 (Haziran/June)

\title{
Bireylerin İnançsızlık Eğilimi: Ateizm Ölçeği
}

Individuals' Tendency to Disbelief: The Atheism Scale

\section{Murat Çinici}

Doktora Öğrencisi, Atatürk Üniversitesi Sosyal Bilimler Enstitüsü, Din Psikolojisi Ana Bilim Dalı - Ph.D. Candidate, Ataturk University Institute of Social Sciences, Department of Psychology of Religion mmurat234@hotmail.com https://orcid.org/0000-0001-6736-0762

\section{Muhammed Kızılgeçit}

Doç. Dr., Atatürk Üniversitesi İlahiyat Fakültesi Din Psikolojisi Bölümü Assoc. Prof. Dr., Ataturk University Faculty of Theology, Department of Psychology of Religion

\author{
mkizilgecit@atauni.edu.tr \\ https://orcid.org/0000-0002-8914-5681
}

\section{Makale Bilgisi - Article Information}

Makale Türü/Article Type: Araştırma Makalesi/ Research Article

Geliş Tarihi/Date Received: 09/02/2021

Kabul Tarihi/Date Accepted: 23/03/2021

Yayın Tarihi/Date Published: 15/06/2021

Atıf/Citation: Çinici, Murat - Kızılgeçit, Muhammed. “Bireylerin İnançsızlık Eğilimi: Ateizm Ölçeği". Sakarya Üniversitesi İlahiyat Fakültesi Dergisi 23/43 (2021), 1-18. https://doi.org/10.17335/sakaifd.877222 .

İntihal: Bu makale, iThenticate yazılımı ile taranmış ve intihal tespit edilmemiştir. Plagiarism: This article has been scanned by iThenticate and no plagiarism detected.

Copyright ( $($ Published by Sakarya Üniversitesi İlahiyat Fakültesi - Sakarya University Faculty of Theology, Sakarya/Turkey. 


\title{
Bireylerin İnançsızlık Eğilimi: Ateizm Ölçeği
}

Öz

Ülkemizde yapılan çalışmalar genellikle İslam inancını ölçmeye yöneliktir. Alanda geliştirilen inanç ve inançsızlık çalışmalarının hem kapsamları yeterli değildir hem de kültürler arası inancın boyutlarına olan yaklaşımdan dolayı farklılıklar içermektedir. Bu araştırmanın amacı; inançsız bireylerin Tanrı'ya olan yaklaşımlarına yönelik geçerli ve güvenilir bir ölçme aracı geliştirmektir. Ölçeğin geliştirilmesi için basit seçkisiz örneklem yöntemiyle 508 kadın, 311 erkek olmak üzere 819 kişi çalışma grubuna dâhil edilmiştir. Ön uygulama için 54, Açımlayıcı Faktör Analizi (AFA) için 462 ve Doğrulayıcı Faktör Analizi (DFA) için 303 kişiye ulaşılmıştır. Ölçeğin faktör yapısını belirlemek amacıyla yapısal eşitlik modellemesi kullanılmıştır. Açıklayıcı ve doğrulayıcı faktör analizlerinin sonucunda birçok inanç faktörlü bir ölçeğin yerine tek boyutlu ateizm ölçeği ortaya çıkmıştır. Ölçeğin Kaiser-Meyer-Olkin (KMO) değeri ,880 ve Bartlett's Küresellik Testi değeri ise $* X^{2}=1395.249 ; d f=15, p<, 001$ için anlamlı bulunmuştur. Ölçeğin Cronbach's Alpha güvenirlik kat sayısı ilk başta , 96 olarak bulunmuştur.

Anahtar Kelimeler: Ateizm, İnanç, Ölçek Geliştirme, Geçerlik, Güvenirlik.

\section{Individuals' Tendency to Disbelief: The Atheism Scale}

\begin{abstract}
Studies conducted in our country are generally aimed at measuring Islamic belief. Both the scope of belief and unbelief studies developed in the field are not sufficient, and they are different due to the approach to the dimensions of belief among cultures. The purpose of this research is to develop a valid and reliable measurement tool for the attitudes of unbelievers to God. In order to develop the scale, 819 people, 508 were women, 311 were men, were included in the study group using a simple random sampling method, 54 people were reached for pre-application, 462 for Exploratory Factor Analysis (EFA) and 303 for Confirmatory Factor Analysis (CFA). Structural equation modeling was used to determine the factor structure of the scale. As a result of the explanatory and confirmatory factor analyzes, a one-dimensional atheism scale emerged instead of a scale with many belief factors. The Kaiser-Meyer-Olkin (KMO) value of the scale is .880 and Bartlett's Test of Sphericity is $* X^{2}=1395.249$; df $=15$ was found to be significant for $p<.001$. Cronbach's Alpha reliability coefficient of the scale was initially found to be .96 .

[You may find an extended abstract of this article after the references.]
\end{abstract}

Keywords: Atheism, Belief, Scale Development, Validity, Reliability.

\section{Giriş}

İnanç bir düşünceye gönülden bağlı bulunma, Tanrı'ya, bir dine inanma, birine duyulan güven ve inanılan öğreti demektir. İnanç, zihinsel bir faaliyet ve kavramlar arası bir ilişki; sübjektif olarak kesinlik ifade eden, ruhun deruni tasdikidir. İnanç genel, toplumsal bir nitelikte olup ayn zamanda inanma, şüphe, kanaat gibi ihtimalin bütün derecelerini içerir. ${ }^{1}$ Dini veya spiritüel herhangi bir inanca sahip olmamak anlamına gelen inançsızlık ise düşünce sisteminde Tanrı'ya uygun bir yer bulamamak olan ateizme kadar uzanan bir çizgide farklı şekillerde kendini gösterebilmektedir. Ateizmin yanı sıra, bir başka varlığı Tanrı yerine koymak olarak da tanımlanabilmektedir. Birden çok Tan-

1 Muhammed Kızılgeçit, Din Psikolojisinin 100'ü (Rize: Otto Yayınları, 2017), 22. 
rı'ya inanmak şeklinde özetlenebilecek bir şirk çeşidi olarak da ifade edilebilmektedir. İnançsızlık, dine yönelik inkâr ve ret tutumlarının bir şeklidir. ${ }^{2} \mathrm{Bu}$ araştırmada ele alınan inançsızlık, herhangi bir dine kendini ait hissetmeyen, doğaüstü (metafizik) bir güce veya yaratıcıya inanmayan yani hem dinsiz olmak hem de dikey aşkınlık anlamında spiritüel olmamaktır. Cragun ve arkadaşları tarafından geliştirilen 'dinsizlik ve spiritüel olmayış' ölçeği (NRNSS) inançsızlığı ölçmeye yönelik bir çalışmadır. ${ }^{3}$ Ölçek 8'i dinsizliği ve 8'i de spiritüel olmayışı ölçen toplam 16 maddeden oluşmaktadır. Beşli likert tipte geliştirilen ölçekten düşük puan alınması güçlü dindarlık ve spiritüellik anlamına gelmektedir. ${ }^{4}$ Bahsi geçen çalışma (DİSOL) Sevinç ve arkadaşları tarafından Türkçe 'ye uyarlanmıştır. ${ }^{5}$ Faktör analizi sonucunda orijinalinde yer alan iki boyut, burada da yer almıştır. Din bireylerin ve toplumların hayatında onları şekillendirip yön veren bir değerler sistemidir. Dinin bu fonksiyonuna karşı insanların tutumları olumlu olduğu gibi olumsuz da olmuştur. Din psikolojisi alanında inanç konusu sıkça çalışılmıştır. İnançsızlık ve inkâr konularında yapılan çalışmalar henüz beklenen düzeyde değildir. Sevinç' in karma modelle ortaya koyduğu araştırma ülkemizde inançsızlık üzerine yapılan bir çalışmadır. Bu araştırma, dinin mesajını reddeden kişilerin bu eylemlerinin sebeplerini açıllama üzerinedir. ${ }^{6}$

Dindarlığın tipleri veya boyutları olduğu gibi inançsızlığın boyutları hakkında birçok çalışma yapılmıştır. Bu çalışmaların bazıları kurumsal dinden uzaklaşmayı bazıları ise davranış ve düşüncelerde dinden uzak olmayı inançsızlık olarak ele almıştır. Silver inançsızları kendilerini nasıl tanımladıkları üzerinden altı farklı tipte boyutlandırmıştır. ${ }^{7}$ Bilim ve ilahiyat eğitimi alanında yetkin olanları entelektüel ateist, bilgili ve diğer kişilerle tartışmalara girenleri aktivist ateist, kültürel anlamda dine değer atfeden ve gelenekleri faydalı bulanlara töresel ateist, bilinmeyeni bulmayan çalışanlara arayış içindeki agnostik, tanrı inancına karşı çıkanlara anti- teist ve teist olmayan şeklinde tasnif etmiştir. Sevinç'e göre inançsızlığın boyutlarına göre yapılan çalışmalara bakıldığında, bazılarının inançsızlıkla ilgili epistemolojik tavrı, bazılarının inançsızlığın oluşum biçimini, bazılarının ise duygu-düşünce-davranış arasındaki ilişkiyi temel aldığını görmekteyiz. Kendini inançsız olarak tanımlayan bazı kişiler dini aidiyetini devam ettirirken, kendini inançsız olarak

2 Muhammed Kızılgeçit, Din Psikolojisinin 200'ü (Ankara: Otto Yayınları, 2017), 66.

3 Ryan Cragun vd., “The NonReligious-NonSpiritual Scale (NRNSS): Measuring Everyone from Atheists to Zionists", Science, Religion and Culture 2/3 (2015), 36-53.

4 Cragun vd., "The NonReligious-NonSpiritual Scale (NRNSS): Measuring Everyone from Atheists to Zionists".

5 Kenan Sevinç vd., "Dindar ve Spiritüel Olmama (DíSOL) Ölçeğinin Türkçe'ye Uyarlanması”, Çanakkale Onsekiz Mart Üniversitesi İlahiyat Fakültesi Dergisi 6 (2015), 59-86.

6 Kenan Sevinç, İnançsızlık Psikolojisi (İstanbul: Çamlıca Yayınları, 2017).

7 Christopher Silver vd., "The six types of nonbelief: a qualitative and quantitative study of type and narrative", Mental Health Religion \& Culture 17/10 (2014), 990-1001. 
tanımlamadığı halde bazı kişiler tam bir inançsız gibi yaşamına devam etmektedir. Dolayısıyla inançsızlığı kabul etmek ve inançsız gibi yaşamak farklı inançsızlık tiplerine işaret etmektedir. Öte yandan Tanrı'nın yokluğunu iddia edenler ile Tanrı'nın varlığının ve yokluğunun bilinemeyeceğini iddia edenler farklı tipler olarak görülebilmektedir. ${ }^{8}$ Topuz tarafından inançsızlık, aldatıcı/gösterişçi dindarlık, taklidi dindarlık, tahkiki dindarlık ve zevk alınan dindarlık boyutlarını ölçen, Likert tipte ve 55 maddeden oluşan bir ölçek geliştirilmiştir. ${ }^{9}$ Ölçeğin, yetişkin ve yaşlıların dini inanç ve tutumlarını ölçebildiği ifade edilmiştir. Ayten ve Anık (2014) tarafından LGBT bireyler üzerine yapılan nitel bir araştırmada, bu bireylerin dini eğilimlerini konu edinmektedir. Katılımcıların \%40'1 kendisini "Müslüman" olarak tanımlarken, \%60'1 kendisini "Alevi", "agnostik", "ateist" ve "kararsız" olarak tanımlamıştır. Katılımcılardan inançlı olduğunu söyleyenlerin büyük bir kısmı, kurumsal dinle birlikte bireysel dinî bir yaşama veya manevîyâta yönelik bir tutum içindedir. LGBT bireyler, din hakkında kendi tasavvurlarını oluşturmuşlar ve bu tasavvurları, kişisel hayatlarıyla çelişmeyecek biçimde açıklama eğilimi göstermiştir. ${ }^{10}$

Alanda ateistleri ve agnostikleri araştıran çalışmalara ilgi çoğalmaktadır. ${ }^{11}$ Bu ilginin artmasının sebebi inançsız olarak bilinen ateistlerin sayısının artmış olmasıdır. ${ }^{12}$ Amerika'da son yirmi yılda inançsızlar, din değiştirenler ve deistler üzerine yapılan çalışmalarda, bu kişiler kendilerini "dini olmaktan çok manevi olmak" şeklinde tanımlamışlardır. ${ }^{13}$ Murken yaptığı çalışmada ateizme geçen bireylerin bu değişimlerine sebep olan birçok faktör olduğunu ifade etmiştir. Bu faktörler; din adamlarının hataları, dindar insanlardan dolayı mağduriyet yaşanması, olumsuz tanrı algısı, tanrının insanı cezalandıracak olması, kötülük problemi ve tanrı tarafından terkedilmiş olma hissiyatı

8 Sevinç, İnançsızlık Psikolojisi.

9 İlhan Topuz, "Dindarlık Tipolojilerini Belirleme Ölçeği: Geliştirilmesi, Geçerlilik ve Güvenirlilik Çalışması -Gazali'nin Anlayışına Göre-", Marife 11/3 (2011).

10 Ali Ayten - Evrim Anık, "LGBT Bireylerde Dinî İnanç, Din ve Tanrı Tasavvuru, Dinî ve Manevî Başa Çıkma Süreci", Din Bilimleri Akademik Araştırma Dergisi 14/2 (2014), 7-31.

11 Ralph W. Hood vd., The Psychology of Religion (New York: Guilford Press, ts.); Bruce E. Hunsberger - Bob Altemeyer, Atheists: A Groundbreaking Study of America's Nonbelievers (Amherst: Prometheus Books, 2006); Ariela Keysar, "Who Are America's Atheists and Agnostics?", Secularism and Secularity: Contemporary International Perspectives, ed. Barry A Kosmin - Ariela Keysar (Hartford (CT): Institute for the Study of Secularism in Society and Culture, 2007), 3339.

12 Philip Schwadel, "Period and Cohort Effects on Religious Nonaffiliation and Religious Disaffiliation: A Research Note", Journal for the Scientific Study of Religion 49/2 (2010), 311-319.

13 Penny Marler - Christopher Hadaway, "'Being Religious' or 'Being Spiritual' in America: A Zero-Sum Proposition?", Journal for the Scientific Study of Religion 41/2 (2002), 289-300; Hood vd., The Psychology of Religion; Heinz Streib, "More Spiritual than Religious: Changes in the Religious Field Require New Approaches", Lived Religion - Conceptual, Empirical and PracticalTheological Approaches, ed. Astrid Dinter - Kerstin Söderblom (Brill Publishers, 2008), 53-67. 
şeklindedir. ${ }^{14}$ Pargament'e göre ağır hastalığa yakalanma, sevilen birisinin hayatını kaybetmesi, fiziksel-duygusal veya cinsel istismar sonucu travmaların yaşanması gibi durumlar dinden uzaklaşmayı hızlandırmaktadır. Birey eski inancından koparak ateizme- agnostisizme doğru kaymaktadır. ${ }^{15}$ Son olarak Karaca ve Hacıkeleşoğlu tarafından Tanrı'ya yönelik tahayyül biçimlerini ölçmeye yönelik kültüre duyarlı bir ölçme aracı geliştirilmiştir. ${ }^{16}$ Allah tahayyülleri ölçeğinin birinci faktörü "İlgisiz Allah" (ilgisiz), ikinci faktörü "Korkutan Allah" (korku-ceza yönelimli), üçüncü faktörü "Seven ve korkutan Allah" (dengeli), dördüncü faktörü ise "seven Allah" (sevgi yönelimli) boyutlarından oluşmaktadır.

Bu makalenin konusu bireylerin inançsızlık eğilimidir. Amacı ise bireylerin inançsızlık eğilimini ölçebilen bir ölçeğin geliştirilmesidir. Araştırmanın problem cümlesi: Geçerli ve güvenilir bir ateizm ölçeği hangi özelliklere sahiptir? şeklindedir.

\section{Yöntem}

\section{1. Çalışma Grubu}

Ölçeğin geliştirilmesi amacıyla 15 yaş üzeri bireyler basit seçkisiz örneklem yöntemiyle çalışma grubuna dâhil edilmiştir. Ölçeğin her aşamasında farklı bir grupla çalışılmıştır. Ölçeğin ön uygulaması için 54, Açımlayıcı Faktör Analizi (AFA) için 462 ve Doğrulayıcı Faktör Analizi (DFA) için 303 kişiye uygulama yapılmıştır. Örneklem grubuna ilişkin betimsel istatistikler Tablo 1'de yer almaktadir.

14 Sebastian Murken, Ohne Gott leben: Religionspsychologische Aspekte des "Unglaubens" (Marburg: Diagonal, 2008).

15 Kenneth Pargament, Spiritually Integrated Psychotherapy Understanding and Addressing The Sacred (New York: Guilford, 2007).

16 Faruk Karaca - Hızır Hacikeleşoğlu, "Allah Tahayyülleri Ölçeği”, İlahiyat Tetkikleri Dergisi 54 (2020), 67-83. 
Tablo 1. Örneklem grubuna ilişkin betimsel istatistikler

\begin{tabular}{|c|c|c|c|c|c|c|c|}
\hline \multirow[b]{2}{*}{ Değişkenler } & & \multicolumn{2}{|c|}{$\begin{array}{c}\text { Ön } \\
\text { uygulama }\end{array}$} & \multicolumn{2}{|c|}{ AFA } & \multicolumn{2}{|c|}{ DFA } \\
\hline & & $\mathrm{f}$ & $\%$ & $\mathrm{f}$ & $\%$ & $\mathrm{f}$ & $\%$ \\
\hline \multirow{2}{*}{ Cinsiyet } & Erkek & 20 & 37 & 159 & 34 & 132 & 44 \\
\hline & Kadin & 34 & 63 & 303 & 66 & 171 & 56 \\
\hline \multirow{9}{*}{ Yaş Aralığg } & $15-20$ & 10 & 18 & 71 & 15 & 123 & 41 \\
\hline & $21-30$ & 22 & 41 & 252 & 55 & 117 & 39 \\
\hline & $31-40$ & 15 & 28 & 89 & 19 & 39 & 13 \\
\hline & $41-50$ & 6 & 11 & 39 & 8 & 19 & 5 \\
\hline & $51-60$ & 1 & 2 & 11 & 3 & 5 & 2 \\
\hline & Toplam & 54 & 100 & 462 & 100 & 303 & 100 \\
\hline & En Küçük Yaş & \multicolumn{2}{|c|}{15} & \multicolumn{2}{|c|}{15} & \multicolumn{2}{|c|}{15} \\
\hline & En büyük Yaş & \multicolumn{2}{|c|}{60} & \multicolumn{2}{|c|}{65} & \multicolumn{2}{|c|}{60} \\
\hline & Standart Sapma & \multicolumn{2}{|c|}{10,25} & \multicolumn{2}{|c|}{9} & \multicolumn{2}{|c|}{9} \\
\hline
\end{tabular}

Tanrı'yı monoteist, deist, agnostik, gnostik, panteist ve ateist desenlerinde algılayarak yaklaşan her birey, çalışmanın örneklemi içerisindedir. Ön uygulama aşamasında elde edilen verilerden hareketle monoteist desende yer alan kişilerin, uzman görüşlerine istinaden bu ölçekten çıkarılmasına karar verilmiştir. Dolayısıyla Açıklayıcı Faktör Analizi aşamasında monoteist desende olanlar yoktur. Katılımcıların her desenden olmasına dikkat edilmiştir. Bunun için evreni temsil edecek yeterlilikte örnekleme olması için farklı inanca sahip olan bireylere ulaşılmıştır. Böylece ulaşılabilen tüm inanç desenlerinin uygulamaya katılımı sağlanmıştır.

\section{2. Ölçeğin Geliştirilme Süreci}

Ölçeğin tasarlanma sürecine ilişkin olarak Creswell ve Plano Clark (2015) ile De Vellis'in (2014) önerileri dikkate alınarak süreç tasarlanmıştır. ${ }^{17} \mathrm{Bu}$ kapsamda ölçülecek yapı ve özellikleri belirlenmiştir. Daha sonra ilgili alan yazın incelenerek, inanç ve inançsızlık üzerine yapılmış olan çalışmalar ve bu alanda yapılmış olan belli başlı ölçekler incelenmiştir. Ayrıca uzmanlardan inançların birbirinden ayrılan noktaları üzerine görüşler alınmıştır. Bu doğrultuda 54 maddeden oluşan madde havuzu oluşturulmuştur. Havuzda, bireylerin monoteist, deist, agnostik, gnostik, panteist ve ateist desenlerde

17 John W. Creswell - Plano V.L. Clark, Karma Yöntem Araştırmaları Tasarımı ve Yürütülmesi, ed. Selçuk Beşir Demir - Yüksel Dede (Ankara: Anı Yayıncılık, 2015); Robert F. DeVellis, Ölçek Geliştirme, Kuram ve Uygulamalar, çev. Tarık Totan (Ankara: Nobel, 2017). 
Tanrı'ya olan yaklaşımlarını bilişsel, duygusal ve davranışsal durumları içeren maddelerden oluşan tahmini alt boyutlar oluşturulmuştur. 10 madde monoteizm; 9 madde deizm; 9 madde agnostisizm, 8 madde gnostisizm, 9 madde panteizm ile 9 madde ateizme ilişkindir. Ayrıca ölçekte "Kesinlikle katılmıyorum (1)”, “Katılmiyorum (2)”, "Biraz Katıliyorum (3)”, "Katıliyorum (4)” ve “Kesinlikle katılıyorum (5)" şeklinde beşli Likert tipi derecelendirme kullanılmıştır. Bireylerin Tanrı'ya olan inanç/inançsızlık boyutlarını hassas bir biçimde ölçmek için bu yöntem kullanılmıştır. Ölçülen özelliğe ilişkin verilen yanıtlar olumsuzdan olumluya 1 puan-5 puan aralığında değerlendirilmiştir. 54 maddelik deneme formu, ölçek geliştirme deneyimi olan veya alan uzmanı olan; Dinler Tarihi ve Din Felsefesi dalından ikişer uzman, rehberlik ve psikolojik danışmanlık anabilim dalından bir uzman, din psikolojisi dalından dört uzman olmak üzere yedi alan uzmanı ve iki dil uzmanından görüşler alınmıştır. Yazım ve anlaşılırlık açısından sorunlu görülen maddeler yeniden gözden geçirilmiştir.

İlk aşamada, 54 maddelik ölçek formu ile araştırmacılar tarafından, farklı cinsiyet ve yaş aralığında olan 55 kişiye ön uygulama yapılmıştır. 1 katılımcı cevaplamada rastgele doldurduğu için iptal edilerek, 54 kişi kalmıştır. Kişilerden sözel olarak gelen düzeltmeler ve yorumlar dikkate alınarak, anlamakta güçlük yaşanılan bazı maddeler yeniden düzenlenmiş ve yapılan güvenirlik analizi sonucunda güvenirliği düşük 12 madde çalışma dişı bırakılmış ve anlaşılırlığı düşük bazı ifadeler düzenlenmiştir. Bu işlemlerden sonra 44 maddelik deneme formu ile AFA yapmak için verilerin toplanması sürecine geçilmiştir. AFA aşamasında 7 kişinin cevapları değerlendirmeye alınmayarak 462 katılımcının 52 maddeye verdikleri cevaplar dikkate alınmıştır. $\mathrm{Bu}$ aşamada binişik maddeler ve toplam varyansa etkisi olmayan 40 madde elenmiştir. Geriye kalan üç faktörlü ve 12 maddeli yapı, Doğrulayıcı Faktör analizinde 310 kişiye sunulmuştur. 7 kişinin cevapları dikkate alınmamıştır. Yapılan hesaplamalar ve modifikasyon sonucunda tek faktörlü 6 maddelik bir ölçek ortaya çıkmıştır.

\section{Verilerin Toplanmas1}

Google online form ile örnekleme ulaştırılmıştır. 2020 yılı Kasım ayı içinde, Covid-19 pandemi süreci yasakları dikkate alınarak sadece uzaktan olacak şekilde form doldurulması esas alınmıştır. Ölçek formu, Türkiye'nin her ilinden farklı inanç desenlerine sahip bireylere, çalışmaya gönüllü olarak katılan 834 kişiye uygulanmıştır. Formların 15 tanesi uygun şekilde doldurulmadığından ayıklanmış ve 819 adet ölçek formuna ilişkin demografik veriler ile ölçek maddelerine verilen puanlar istatistik programıyla veri setine dönüştürülmüştür. Araştırmanın verileri 25-29 Kasım 2020 tarihinde toplanmıştır. 


\section{Verilerin Analizi}

Analizlere geçmeden önce verilerin çok değişkenli istatistiğin temel sayıltıları olan normallik, doğrusallık ve örneklem varyanslarının homojenliği (homoscedasticity) test edilmiş ve ayrıca verilerin aşırı skora sahip olup olmadıkları incelenmiştir. Yapılan analiz sonucunda verilerde aşırı skora sahip denek olmadığı ve ayrıca verilerin sözü edilen sayıltıları karşıladı̆̆ı görülmüştür. Araştırmada 462 kişiden alınan yanıtlar kullanılarak ölçeğe ilişkin geçerlik ve güvenirlik analizleri yapılmıştır. Faktör analizi yapabilmek için gereken örneklem büyüklüğü incelenmiştir. Araştırmada örneklem büyüklüğü açısından yeterli sayıya ulaşılmıştır. "Farklı inançlara sahip bireylerin, Tanrı'ya olan yaklaşımlarının" boyutları ve boyutlarda yer alan maddeler AFA ile belirlenmiş, elde edilen yapının geçerliliğini sınamak için de DFA yapılmıştır. Ayrıca, ölçeğin tamamı ve alt boyutları için Cronbach Alfa ve iki yarı güvenirlik katsayıları belirlenmiştir.

\section{Bulgular}

\section{Geçerliliğge İlişkin Bulgular}

Bir ölçme aracının geçerliliği çeşitli yöntemlerle incelenir.

\subsection{Açımlayıcı Faktör Analizi}

Maddelerin güvenirlik analizleri yapılmış ve tüm maddelerin uygun değerlere sahip olduğu görülmüştür. Toplanan verilere ilişkin olarak, yapı geçerliğini sağlamak için AFA yapılmıştır. AFA'da ölçekte yer alacak maddeleri belirlenmede madde öz değerlerinin 1, maddelerin yük değerinin en az .30, iki faktörde yer alan faktörler arasında en az .10 fark olması yani binişik madde olmaması dikkate alınmıştır. ${ }^{18}$

Örneklem büyüklüğünün AFA için uygun olup olmadığını belirlemek için ise Kaiser- Meyer-Olkin (KMO) testine bakılmıştır. KMO değeri 950 olarak elde edildiğinden AFA yapılabileceği kararlaştırılmıştır. KMO değeri hesaplandiktan sonra Bartlett's Sphericity testi incelenmiş ( $\chi 2=9763.437, p=.000)$, edinilen veriler anlamlı farklılık gösterdiğinden, değerlerin faktör analizi yapmak için uygun olduğu belirlenmiştir. AFA yapılmış ve ilk verilerle ölçeğin yedi faktörlü bir yapı gösterdiği görülmüştür. Ancak, iki faktörde bulunan maddelerin yükleri arasında .10 'dan fazla fark olan yani binişik madde özelliği gösteren 30 madde ölçekten çıkarılmış ve yeniden AFA yapılmıştır.

18 Şener Büyüköztürk, Sosyal Bilimler İçin Veri Analizi El Kitabı (Ankara: Pegem Akademi, 2007); İsmail Seçer, Psikolojik Test Geliştirme ve Uyarlama Süreci: SPSS ve LISREL Uygulamaları (Ankara: Anı Yayıncılık, 2015), 87. 
Şekil 1. Çizgi Grafiği Faktör Yapısı

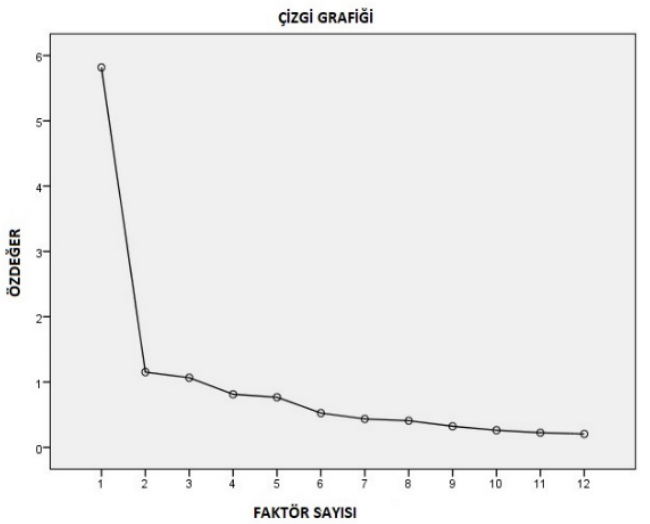

Şekil 1'de görüldüğü üzere, geçerlik çalışmalarına ilişkin olarak yapilan faktör analizleri, Scree Plot (Çizgi) Grafiği ölçeğin 12 madde ve üç faktörden oluşan bir yapıda olduğunu göstermiştir. 12 maddeyle yapılan AFA'da KMO değeri .898 bulunmuştur. Bartlett's Sphericity testine bakılarak $\left(\chi^{2}=2930.419\right.$, p.=.000) elde edilen değerlerin faktör analizi için uygun olduğu belirlenmiştir. Faktör analizi yöntemlerinden "Maximum Likelihood" in en iyi sonuç verdiği görülmüştür. Ayrıca çevirme yöntemi olarak "Equamax" kullanılmıştır. Yeni durumda üç faktörlü bir yapı oluşmuştur.

Maddelere ait faktör yükleri Tablo 2'de sunulmuştur.

Tablo 2: Rotated Factor Matrixa

\begin{tabular}{|c|c|c|c|}
\hline & \multicolumn{3}{|c|}{ Factor } \\
\hline & 1 & 2 & 3 \\
\hline $\mathrm{m} 24$ & ,805 & & \\
\hline m18 & ,730 & & \\
\hline $\mathrm{m} 48$ & 672 & & \\
\hline m6 & ,629 & & \\
\hline m30 & ,538 & & \\
\hline $\mathrm{m} 42$ & ,350 & & \\
\hline m34 & & 820 & \\
\hline m10 & & 764 & \\
\hline $\mathrm{m} 4$ & & 618 & \\
\hline $\mathrm{m} 12$ & & & 906 \\
\hline m36 & & & 728 \\
\hline $\mathrm{m} 2$ & & & 329 \\
\hline
\end{tabular}


Tablo 2 incelendiğinde; 1 . faktörün 24, 18, 48, 6, 30, ve 42. maddeler olmak üzere altı maddeden oluştuğu ve maddelerin faktör yüklerinin .35 ve .80 arasında değiştiği görülmektedir. Ölçeğe ilişkin toplam varyansın \%22,87'ini açıklayan birinci faktör "Ateizm" şeklinde adlandırılmıştır. Bu faktörün maddeleri;

m24-"Yaratıcının var olmadığını düşünüyorum",

m18-"Yaratıcının var olmadığını biliyorum",

m6-"Yaratıcının var olduğuna inanmıyorum",

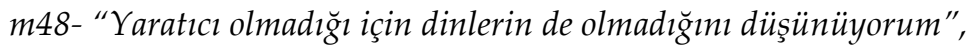

m30-"Yaratıcının varlı̆̆ına inanmıyorum",

m42-“Yaratıcıya inanmamanın insanı özgürleştireceğini düşünüyorum", şeklindedir.

Ölçekte yer alan 2. faktörün 34, 10 ve 4. maddeler olmak üzere üç maddeden oluştuğu ve maddelerin faktör yüklerinin .61 ve .82 arasında değiştiği görülmektedir. Ölçeğe ilişkin toplam varyansın \%18.73'ünü açıklamaktadır. Ölçekte yer alan 3 . faktörün 12,36 ve 2 . maddeler olmak üzere üç maddeden oluştuğu ve maddelerin faktör yüklerinin .32 ve .90 arasında değiştiği görülmektedir. Ölçeğe ilişkin toplam varyansın \%16,94'ünü açıklamaktadır.

12 maddeden oluşan ölçek bütün olarak incelendiğinde, üç faktörlü bir yapıda olduğu görülmektedir. Ölçekte yer alan 12 maddenin faktörlerdeki yük değerlerinin 0.32-0,90 arasında değiştiği görülmektedir. Ölçekte bulunan üç faktör toplam varyansın \%58,55'ini açıklamaktadır. Elde edilen değerler ölçeğin, bireylerin Tanrı'ya olan inançlarını açıklamada yeterli olduğunu göstermektedir.

\subsection{Doğrulayıcı Faktör Analizi}

AFA ile elde edilen yapı DFA ile test edilmiştir. Garson'un (2010) önerisi doğrultusunda ${ }^{19}$ faktör yükleri incelenerek, düşük değere sahip 2, 12, 36, 4, 10 ve 34. maddeler ölçekten çıkarılmıştır. Böylece son durumda 6 maddeden oluşan tek faktörlü bir yapı ortaya çıkmıştır. Ayrıca DFA'da yapılan modifikasyon önerileri doğrultusunda m42 ile m48 maddeleri arasında modifikasyon yapılması uygun görülmüştür. Yapılan modifikasyonun $\chi^{2{ }^{\prime}}$ ye (ki-kare) katkı sundukları görülmüştür. DFA sonucunda, uyum indeksi değerleri $\chi^{2}=10,749$ (sd=216, p.=.00), $\chi^{2} / \mathrm{sd}=1,34, \mathrm{SRMR}=.009, \mathrm{RMSEA}=.034, \mathrm{GFI}=.98, \mathrm{AGFI}=.97$, $\mathrm{CFI}=.99, \mathrm{NFI}=0.99$ olarak bulunmuştur. Uyum indekslerine ilişkin elde edilen önemli değerler ve uyum düzeyleri Tablo 3'de sunulmuştur. Uyum değerleri Byrne'nin (2011) belirttiği referans değerleri dikkate alınarak değerlendirilmiştir. ${ }^{20}$

19 George David Garson, "Factor Analysis' from Statnotes: Topics in Multivariate Analysis." (2009).

20 Barbara M Byrne, Structural Equation Modeling With AMOS Basic Concepts, Applications, and Programming, (New York: Routledge, ts.). 
Şekil 2. Ateizm Ölçeği DFA Sonuçları (Faktör Yapısı)

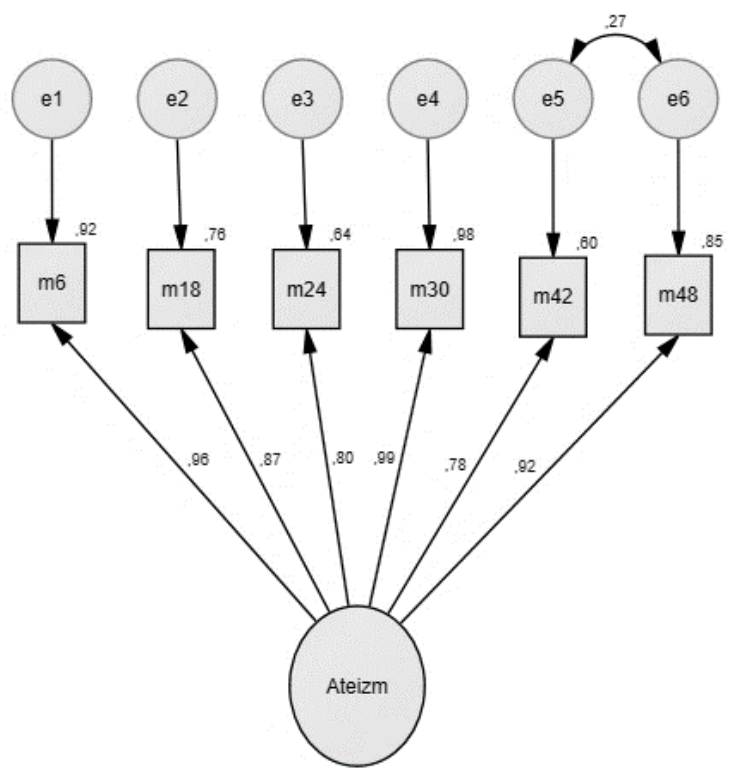

Standart çözümlerin ardından maddefaktör ilişkisini gösteren path diyagramı incelenmiş ve elde edilen değerlerin madde-faktör uyumu açısından uygun olduğu belirlenmiştir. Maddelere ilişkin faktör yapısını gösteren path diyagramı Şekil 2'de görülmektedir.

Tablo 3. DFA'ya İlişkin Uyum İndeksleri

\begin{tabular}{lllll}
\hline İndeksler & \multicolumn{2}{l}{ Referans Değer } & Ölçüm & Sonuç \\
\cline { 2 - 5 } & İyi Uyum & Kabul Edilir Uyum & & \\
\hline CMIN/DF & $0<\chi^{2} / \mathrm{sd} \leq 3$ & $3<\chi^{2} / \mathrm{sd} \leq 5$ & 1,34 & İyi uyum \\
TLI & $.95<\mathrm{TLI} \leq 1$ & $.90<\mathrm{TLI} \leq .94$ & .99 & İyi uyum \\
RMSEA & $0 \leq \mathrm{RMSEA} \leq .05$ & $.05 \leq \mathrm{RMSEA} \leq .08$ & .034 & İyi uyum \\
SRMR & $0 \leq \mathrm{SRMR} \leq .05$ & $0.05 \leq \mathrm{SRMR} \leq .10$ & .009 & İyi uyum \\
CFI & $.95<\mathrm{CFI} \leq 1$ & $.90<\mathrm{CFI} \leq .94$ & .99 & İyi uyum \\
Sd & & & 216 &
\end{tabular}

Ölçeğin maddelerinin birbirleri ve toplamıyla korelasyonunun belirlenmesi amacıyla yapılan Pearson Korelasyon analizi sonuçları Tablo 4'de yer almaktadır. 
Tablo 4. Ölçek Maddeleri ve Toplam Puana İlişkin Korelasyon Analizi Sonuçları

\begin{tabular}{|c|c|c|c|c|c|c|c|}
\hline & Toplam & $\mathrm{m} 24$ & $\mathrm{~m} 18$ & $\mathrm{~m} 48$ & $\mathrm{~m} 6$ & $\mathrm{~m} 30$ & $\mathrm{~m} 42$ \\
\hline Toplam & \multirow[t]{7}{*}{1,00} & \multirow{7}{*}{$\begin{array}{l}, 85^{* *} \\
1,00\end{array}$} & \multirow{7}{*}{$\begin{array}{l}, 89^{* *} \\
73^{* *} \\
1,00\end{array}$} & \multirow{7}{*}{$\begin{array}{l}, 94^{* *} \\
, 73^{* *} \\
, 80^{* *} \\
1,00\end{array}$} & \multirow{7}{*}{$\begin{array}{l}, 94^{* *} \\
75^{* *} \\
84^{* *} \\
88^{* *} \\
1,00\end{array}$} & \multirow{7}{*}{$\begin{array}{l}96^{* *} \\
79^{* *} \\
85^{* *} \\
91^{* *} \\
95^{* *} \\
1,00\end{array}$} & $84^{* *}$ \\
\hline $\mathrm{m} 24$ & & & & & & & ,63 \\
\hline $\mathrm{m} 18$ & & & & & & & $67^{* *}$ \\
\hline $\mathrm{m} 48$ & & & & & & & ,78 \\
\hline $\mathrm{m} 6$ & & & & & & &, $73^{* *}$ \\
\hline $\mathrm{m} 30$ & & & & & & &, $77^{* *}$ \\
\hline $\mathrm{m} 42$ & & & & & & & 1,00 \\
\hline
\end{tabular}

Tablo 4'deki bulgular incelendiğinde; ölçeğin toplam puanı ile maddeleri arasında pozitif yönde yüksek düzeyde bir ilişkinin olduğu görülmektedir. Ölçeğin maddeleri arasındaki korelasyon düzeylerinin ise $(r=.63)$ ile $(r=.96)$ arasında değiştiği görülmektedir. Ölçeğin tek faktörü olduğu için faktörler arası korelasyon analizi yapılmamıştır.

Sonuç olarak "Ateizm" şeklinde adlandırılan faktörün m24 (,903), m18 $(, 801), \mathrm{m} 48(, 840), \mathrm{m} 6(, 730), \mathrm{m} 30(, 623)$, ve $\mathrm{m} 42(, 466)$ olmak üzere altı maddeden oluştuğu ve maddelerin faktör yüklerinin son durumda , 46 ve ,90 arasında değiştiği görülmektedir. Toplam varyans ise 55,02'tir.

\subsection{Eşzamanlı (Birlikte / Uyum) Geçerlilik}

Geçerliliği sınanan ölçek ile birlikte geçerliliği daha önceden ortaya konmuş ve aynı alanda kullanılan başka bir ölçek uygulanır ve iki ölçek arasındaki bağıntıya bakılır. Elde edilen korelasyon katsayısı, ölçeğin eş zamanlı geçerliliğini gösterir.

Tablo 5: Disol Ölçeği ve Ateizm Ölçeğine Ait Korelasyon Sonuçları

\begin{tabular}{r|c}
\hline & Ateizm Ölçeği \\
\hline Dindar ve Spiritüel Olmama (DİSOL) Ölçeği & \\
Korelasyon & 0,857 \\
Anlamlılık (sig) & 0,001 \\
Katılımcı Sayısı & 62 \\
\hline
\end{tabular}

$\mathrm{p}<0,005$

Geçerliliği sınamak için alanda kullanılan 'Dindar ve Spiritüel Olmama (DİSOL) Ölçeği' ve 'Ateizm Ölçeği' 62 kişiye uygulanmıştır. İki ölçekten elde edilen ortalama puanlar arasındaki korelasyona ait veriler Tablo 5 'te verilmiştir. Disol ölçeğinden alınan düşük puan bireyin dindar olmadığını ve ateizm 
ölçeğinden elde edilen düşük puan yaratıcıya inanmadığını ve kabul etmediğini ortaya koymaktadır. İki ölçek arasında pozitif yönde yüksek düzeyde (,86) bir ilişki olduğu görülmektedir.

\section{Güvenirliğe İlişkin Bulgular}

\section{1. İç Tutarlılık (Cronbach Alfa) Kat Sayıları}

Analizler sonucunda son şekli verilen ölçeğin 6 maddeye ilişkin güvenirlik analizleri için Cronbach Alfa iç tutarlılık katsayısı hesaplanmış olup, ölçeğin bütünü için 0,95 olarak hesaplanmıştır. Elde edilen değerler, ölçeğin çok yüksek güvenirliğe sahip olduğunu göstermektedir. ${ }^{21}$

\section{2. İki Yan Güvenirlik Kat Sayısı}

Ölçeğin 6 maddeden oluşan son şekline ilişkin iki yarı güvenirlik analizi sonucunda ölçeğin Spearman-Brown korelasyon değeri $(r=, 96)$ uygun değerde ${ }^{22}$ ve iki yarıya ilişkin Cronbach alfa güvenirlik katsayılarının uygun değerlerde olduğu söylenebilir. İki yarı güvenirlik katsayıları Tablo 6' de verilmiştir.

Tablo 6: Iki Yarı Güvenirlik Analizi Sonuçları

\begin{tabular}{ll}
\hline İki Yarı & Cronbach Alfa \\
\hline 1. K1sım &, 91 \\
2. K1sım &, 90 \\
\hline
\end{tabular}

Tablo 6'da iki yarı güvenirlik analiz sonuçları ölçeğin güvenilir bir ölçek olduğunu göstermektedir.

\section{Sonuç ve Tartışma}

$\mathrm{Bu}$ çalışmanın temel amacı dar anlamda teist olmamak veya bireysel bir tanrıya inanmayı reddetme şeklinde tanımlanan ateizme ait bir ölçek geliştirilmesidir. Geliştirilen ölçek bireylerin ateizme yakınlığı veya teizmden ne kadar uzaklaştığına dair yatkınlığını ölçmektedir. Öncelikli olarak monoteizm, deizm, agnostisizm, gnostizim, panteizm ve ateizm boyutlarına sahip bir ölçek geliştirilmesi planlanmıştır. Pilot uygulamanın verilerinden hareketle monoteizme ait maddelerin başka bir ölçek çalışmasının konusu olacağı alan uzmanları tarafından tavsiye edilmiştir. Bu amaçla 10 madde başka bir çalışma

21 Kazım Özdamar, Eğitim, Sağlık ve Davranış Bilimlerinde Ölçek ve Test Geliştirme Yapısal Eşitlik Modellemesi: IBM SPSS, IBM SPSS AMOS ve MINITAB uygulamalı (Eskişehir: Nisan Kitabevi, 2017).

22 Seçer, Psikolojik Test Geliştirme ve Uyarlama Süreci: SPSS ve LISREL Uygulamaları, 24. 
için temel oluşturmuştur. Ayrıca güvenilirliği düşüren 2 madde de çıkarılmıştır. Bu doğrultuda geriye kalan 42 maddelik maddelerden elde edilen verilere ilk olarak AFA yapılmış, 12 madde ve üç faktörden oluşan (ateizm- deizmagnostisizm) bir yapı elde edilmiştir. AFA ile elde edilen yapıya, DFA yapılarak model uyumu incelenmiştir. DFA sonucunda, 6 madde daha çalışma dişı bırakılmış "ateizm" adında tek faktörlü, 6 maddeden oluşan bir yapı elde edilmiştir. Daha sonra güvenirlik analizleri yapılmış ve ölçeğin bütününe ilişkin iç tutarlılık katsayısı .95 olarak hesaplanmıştır.

Madde havuzu oluşturulurken inançlı ve inançsız insanların Tanrı'yı tanımlamalarının farklılığı göz önünde bulundurularak, "yaratıcı" denilmesi uygun görülmüştür. Maddelerin içeriği felsefi anlamda ateizm düşüncesine uygun olması gerekçesiyle, ateizm ölçeğinin başka dillere uyarlama yapılarak öteki kültürlerde kullanılması uygundur. Tek faktörlü bir yapıda olması ateizmin tanrıya yönelik yaklaşımı ile ilgilidir. Ölçeğin başından sonuna kadar ki psikometrik süreci göz önüne alındığında hem monoteist hem ateist bir ölçeğin farklı boyutlarda yer alarak tek bir ölçek şeklinde geliştirilmeyeceği ortaya çıkmıştır. Buna bağlı olarak araştırmacıların kendi çalışmalarında ateizm ölçeğiyle birlikte monoteizm ölçeğini de kullanmaları mümkündür.

Deizm, agnostisizm, panteizm ve gnostizm gibi yaklaşımların birbirinden net çizgilerle ayrılmasının ölçeklerde mümkün olmadığı varsayılsa da yapılacak çalışmalarda farklı boyutlarla ölçeklerin geliştirilmesine teşebbüs edilebilir. Nitekim çalışmamızın başında altı boyutlu bir inanç ölçeği hedeflenmiş olsa da maddelerin birlikte güvenirliği sağlayamadığı görülmüştür. Bundan sonraki çalışmalarda Ateizm Ölçeği'nin, nicel ve nitel olarak farklı örneklemlerde denenmesinin ölçeğin geçerlik ve güvenilirliği konusunda daha sağlam ve genellenebilir sonuçlara ulaşılması konusunda yardımcı olacaktır.

\section{Kaynakça}

Ayten, Ali - Anık, Evrim. “LGBT Bireylerde Dinî İnanç, Din ve Tanrı Tasavvuru, Dinî ve Manevî Başa Çıkma Süreci”. Din Bilimleri Akademik Araştırma Dergisi 14/2 (2014), 7-31.

Büyüköztürk, Şener. Sosyal Bilimler İçin Veri Analizi El Kitabı. Ankara: Pegem Akademi, 2007.

Byrne, Barbara M. Structural Equation Modeling With AMOS Basic Concepts, Applications, and Programming. New York: Routledge, Third Edition, ts.

Cragun, Ryan vd. "The NonReligious-NonSpiritual Scale (NRNSS): Measuring Everyone from Atheists to Zionists". Science, Religion and Culture 2/3 (2015), 36-53.

Creswell, John W. - Clark, Plano V.L. Karma Yöntem Araştırmaları Tasarımı ve Yürütülmesi. ed. Selçuk Beşir Demir - Yüksel Dede. Ankara: Anı Yayıncılık, 2. Basım., 2015.

DeVellis, Robert F. Ölçek Geliştirme, Kuram ve Uygulamalar. çev. Tarık Totan. Ankara: Nobel, 3. basim, 2017. 
Garson, George David. "'Factor Analysis' from Statnotes: Topics in Multivariate Analysis." 2009. Erişim 17 Şubat 2021. https://faculty.chass.ncsu.edu/garson/PA765/statnote.htm

Hood, Ralph W. vd. The Psychology of Religion. New York: Guilford Press, Fifth Edition, ts.

Hunsberger, Bruce E. - Altemeyer, Bob. Atheists: A Groundbreaking Study of America's Nonbelievers. Amherst: Prometheus Books, 2006.

İlhan Topuz. "Dindarlık Tipolojilerini Belirleme Ölçeği: Geliştirilmesi, Geçerlilik ve Güvenirlilik Çalışması -Gazali'nin Anlayışına Göre-". Marife 11/3 (2011). https://www.marife.org/marife/article/view/610

Karaca, Faruk - Hacikeleşoğlu, Hızır. "Allah Tahayyülleri Ölçeği”. İlahiyat Tetkikleri Dergisi 54 (2020), 67-83.

Keysar, Ariela. "Who Are America's Atheists and Agnostics?" Secularism and Secularity: Contemporary International Perspectives. ed. Barry A Kosmin - Ariela Keysar. 33-39. Hartford (CT): Institute for the Study of Secularism in Society and Culture, 2007.

Kızılgeçit, Muhammed. Din Psikolojisinin 100'ü. Rize: Otto Yayınları, 2017.

Kızılgeçit, Muhammed. Din Psikolojisinin 200'ü. Ankara: Otto Yayınları, 2017.

Marler, Penny - Hadaway, Christopher. "'Being Religious' or 'Being Spiritual' in America: A Zero-Sum Proposition?" Journal for the Scientific Study of Religion 41/2 (2002), 289-300.

Murken, Sebastian. Ohne Gott leben: Religionspsychologische Aspekte des "Unglaubens". Marburg: Diagonal, 2008.

Özdamar, Kazım. Eğitim, Sağlık ve Davranış Bilimlerinde Ölçek ve Test Geliştirme Yapısal Eşitlik Modellemesi: IBM SPSS, IBM SPSS AMOS ve MINITAB uygulamalı. Eskişehir: Nisan Kitabevi, 2017.

Pargament, Kenneth. Spiritually integrated psychotherapy. Understanding and addressing the sacred. New York: Guilford, 2007.

Schwadel, Philip. "Period and Cohort Effects on Religious Nonaffiliation and Religious Disaffiliation: A Research Note". Journal for the Scientific Study of Religion 49/2 (2010), 311-319.

Seçer, İsmail. Psikolojik Test Geliştirme ve Uyarlama Süreci: SPSS ve LISREL Uygulamaları. Ankara: Anı Yayıncılık, 2015.

Sevinḩ̧, Kenan vd. “Dindar ve Spiritüel Olmama (DİSOL) Ölçeğinin Türkçe’ye Uyarlanması". Çanakkale Onsekiz Mart Üniversitesi İlahiyat Fakültesi Dergisi 6 (2015), 59-86.

Sevinç, Kenan. İnançsızlık Psikolojisi. İstanbul: Çamlıca Yayınları, 2017.

Silver, Christopher vd. “The six types of nonbelief: a qualitative and quantitative study of type and narrative". Mental Health Religion \& Culture 17/10 (2014), 990-1001.

Streib, Heinz. "More Spiritual than Religious: Changes in the Religious Field Require New Approaches". Lived Religion - Conceptual, Empirical and Practical-Theological Approaches. ed. Astrid Dinter - Kerstin Söderblom. 53-67. Brill Publishers, 2008. 


\section{Individuals' Tendency to Disbelief: The Atheism Scale}

\section{(Extended Abstract)}

\section{Introduction}

Faith means devotion to thought, faith in God, and religion, trust in someone, and a doctrine to be believed. Faith is a mental activity and relationship between concepts; it is the deep affirmation of the soul that expresses subjectively certainty. Belief has a general and social quality, and at the same time includes all degrees of possibility such as belief, doubt, conviction. The disbelief discussed in this research is not feeling of belonging to any religion, not believing in a supernatural (metaphysical) power or creator, not being spiritual in the sense of both irreligious and vertical transcendence. There is growing interest in studies investigating atheists and agnostics in the field.

\section{Method}

In order to develop the scale, individuals over the age of 15 were included in the study group using a simple random sampling method. Each stage of the scale was worked with a different group. The pre-application of the scale was applied to 54 people, 462 for Exploratory Factor Analysis (EFA) and 303 for Confirmatory Factor Analysis (CFA). Descriptive statistics for the sample group are included in Table 1. This scale has been developed to measure the attitudes of unbelievers towards God. All kinds of people are included in the sample, whether they believe it or not. Each individual who perceives God in monotheist, deist, agnostic, gnostic, pantheist, and atheist patterns is included in the sample of the study. Based on the data obtained in the pre-application phase, and expert opinions it was decided to exclude the people in the monotheist pattern from this scale. Therefore, there are no monotheist designs in the Explanatory Factor Analysis phase. Attention was paid to the participants to come from every pattern. For this, individuals with different designs were reached in order to have sufficient sampling to represent the universe. Thus, the participation of all the belief patterns that could be reached in the practice was provided.

An item pool consisting of 54 items was created. In the pool, estimated subdimensions consisting of items including cognitive, emotional, and behavioral states of individuals' approaches to God in monotheist, deist, agnostic, gnostic, pantheist, and atheist patterns were created. 10 items are about monotheism; 9 items deism; 9 items agnosticism, 8 items Gnosticism, 9 items pantheism, and 9 items atheism. In addition, a five-point Likert-type rating such as "Strongly disagree (1)", "Disagree (2)", "Somewhat Agree (3)", "Agree (4)", and "Strongly Agree (5)" was used in the scale. In the first stage, a pre-appli- 
cation was made to 55 people from different sex and age ranges by the researchers with the 54-item scale form. 1 participant was canceled because of randomly filling in the answer, and 54 people are examined. Considering the verbal corrections and comments from individuals, some items that were difficult to understand were rearranged and as a result of the reliability analysis, 12 items with low reliability were excluded from the study, and some expressions with low comprehensibility were arranged. After these procedures, the process of collecting data for EFA was started with the 44-item trial form.

Factor analysis regarding validity studies showed that the Scree Plot Graph scale consists of 12 items and three factors. In EFA with 12 items, KMO value was found to be .898 . By looking at Bartlett's Sphericity test $(2=2930.419$, $\mathrm{p}=.000$ ), it was determined that the values obtained were suitable for factor analysis. It was seen that "Maximum Likelihood", one of the factor analysis methods, gave the best results. In addition, "Equamax" has been used as a conversion method. In the new case, a three-factor structure has been formed.

The structure obtained with AFA was tested by DFA. In line with the suggestion of Garson (2010), the factor loadings were examined and items 2, 12, $36,4,10$ and 34 with low values were removed from the scale. Thus, in the last case, a single factor structure consisting of 6 items emerged. In addition, in line with the modification suggestions made in DFA, it was deemed appropriate to make modifications between $\mathrm{m} 42$ and $\mathrm{m} 48$ items. It has been observed that the modification made contributes to $\chi^{2}$ (chi-square). As a result of CFA, fit index values are $2=10.749(\mathrm{sd}=216, \mathrm{p} .=.00), \chi^{2} / \mathrm{df}=1.34, \mathrm{SRMR}=.009$, RMSEA=.034, GFI=.98, AGFI=.97, CFI=.99, NFI=0.99.

A relationship has been identified as follows: it is positively high between the total score of the scale and item $24(\mathrm{r}=.85)$, it is positively high between the total score of the scale and item $18(\mathrm{r}=.89)$, it is positively high between the total score of the scale and item $48(\mathrm{r}=.94)$, it is positively high between the total score of the scale and item 6 , it is high in the direction $(\mathrm{r}=.94)$, it is positively high between the total score of the scale and item $30(\mathrm{r}=.96)$ and it is positively high between the total score of the scale and item 42 ( $\mathrm{r}=.84)$. It is seen that the correlation levels between the items of the scale vary between $(r=.63)$ and $(r=.96)$. Since it is the only factor of the scale, correlation analysis between factors was not performed.

\section{Discussion-Conclusion}

In the study, it was aimed to develop a valid and reliable scale for determining individuals' belief in God. In this direction, EFA was first applied to the data obtained from the remaining 42-item items, and a structure consisting of 12 items and three factors (atheism-deism-agnosticism) was obtained. Model fit was examined by DFA to the structure obtained with EFA. As a result of CFA, 6 more items were excluded from the study, and a structure called "atheism" 
with a single factor and consisting of 6 items was obtained. Then, reliability analyzes were made and the internal consistency coefficient for the whole scale was calculated as .95 . 